\title{
Leadership training for pharmacists
}

IN OUR OPINION, LEADERSHIP DEVELOPMENT IS A RESEARCHsparse area of the pharmacy profession. As such, we would like to open by applauding the efforts of Shikaze et al. ${ }^{1}$ for conducting and reporting research in this critical area. The "hard to hear" but honest assessments from their work provide substantial evidence of the need for further leadership development in our profession. We concur with the paper's recommendation for formal education and structural incentives for leadership. Upon reflection, their findings, while incredibly valuable, are not all that surprising; leadership is only 1 of 7 key competencies, or roles, described in the Association of Faculties of Pharmacy in Canada (AFPC) Educational Outcomes for First Professional Degree Programs in Pharmacy. ${ }^{2}$ Furthermore, the leadership role from AFPC is split with management. Although, in practice, potential overlap exists between the 2 roles, they require distinct skillsets. ${ }^{3}$ Considering all competing priorities, pharmacy education may not fully prepare individuals with the needed leadership skills for their career and to advance the profession. We would like to address activity in the area of leadership education.

As noted by Shikaze et al., ${ }^{1}$ leadership is not just for those with management positions but important for all pharmacists to advance their pharmacy practice. A key conclusion from the respondents was the lack of interpersonal skills and readiness for leadership. Most felt unprepared and undereducated for a leadership role, and they reported feeling as though this could be addressed through formal education. The authors of this letter agree that education can help pharmacists build their leadership skills and the confidence needed to apply them. Formal training in leadership must be integrated into pharmacy degree programs. In addition, pharmacists who wish to pursue further their leadership skills can complete programs such as the University of Cincinnati's Online Graduate Programs in Pharmacy Leadership to obtain a graduate certificate or master's degree. Full program details can be found at the website (pharmacy.uc.edu/leader).

The inaugural class of the master's degree track, of which one of this letter's authors (ZD) was a member, convocated in April 2018. Compared with MBA or MHA programs, one of the noted advantages of the Master in Pharmacy Leadership program is the opportunity to develop leadership and management competencies while in a pharmacy context. For example, when studying finance and accounting, the learning material and cases focus specifically on medication budgets. The skills are transferable to other types of accounting, but they are immediately practical to pharmacy. Further examples include change management discussions, which leverage the concepts of clinical and lateral leadership. Nontraditional leadership roles are not unique to pharmacy, but these pharmacy-based models serve as realistic learning opportunities.

The ability to gain broader perspectives by interacting through assignments with pharmacists from all practice areas (e.g., community, hospital, academia, advocacy, etc.) is critical at a time when the profession has experienced significant change and is looking to unify its identity. ${ }^{4}$ Also appreciated are the opportunities to develop ancillary competencies in research, project management, telecommunications, time management and maintaining work-life balance. The part-time and asynchronous curriculum allows for coursework completion among already busy lives. Furthermore, participating via correspondence has allowed for completion from afar-even across national borders-eliminating the need to pick up and move.

Employer staff development support, as well as scholarships, foundations and grants, could provide the structural and financial incentives needed to allow aspiring pharmacists to pursue formal training. Educating future pharmacy leaders is critical to building a sustainable leadership workforce that will ensure the profession continues to advance and improve medication use through patient care.

Zack Dumont, BSP, ACPR, MS (Pharm)

Pharmacy Services (Regina), Saskatchewan Health Authority

Regina General Hospital

Regina, Saskatchewan

Jenelle Sobotka, PharmD, FAPhA, FNAP

Neil J. MacKinnon, BSc (Pharm), MS (Pharm), PhD, FCSHP,

FNAP

James L. Winkle College of Pharmacy

University of Cincinnati

Cincinnati, Ohio 
ORCID iD: Zack Dumont (iD https://orcid.org/0000-0001-5296-2488

\section{References}

1. Shikaze D, Arabi M, Gregory P, Austin Z. Community pharmacists' attitudes, opinions and beliefs about leadership in the profession: an exploratory study. Can Pharm J (Ott) 2018;151:315-21.

2. AFPC Educational Outcomes for First Professional Degree Programs in Pharmacy in Canada 2017. Available: www.afpc.info/content/2017-educat ional-outcomes (accessed October 10, 2018).
3. Zaleznik A. Managers and leaders: are they different? Harvard Business Review. January 2004. Available: https://hbr.org/2004/01/managers-andleaders-are-they-different?referral $=03758 \& \mathrm{~cm}$ _vc $=r$ r_item_page.top_right (accessed October 10, 2018).

4. Tsuyuki RT, Houle SK, Okada H. Time to give up on expanded scope of practice. Can Pharm J (Ott) 2018;151(5):286. 